\title{
Late results of endoscopic sphincterotomy for bile duct stones in elderly patients with gall bladders in situ
}

\author{
C J H INGOLDBY, J EL-SAADI, R I HALL, AND M E DENYER \\ From the University Department of Surgery, St James's University Hospital, Leeds and Department of \\ Medicine, Seacroft Hospital, Leeds
}

SUMMARY Endoscopic sphincterotomy was undertaken in 186 patients with common bile duct stones and an intact gall bladder who were considered unfit for surgery. One hundred and seventy one patients had jaundice of whom 18 also had clinical cholangitis. The mean age of treated patients was 79.7 years (range 27-92) and only 13 were aged less than 60. Sphincterotomy was successful in $185(99 \%)$ and complete clearance achieved in $172(92 \cdot 5 \%)$. Early complications occurred in nine patients $(4 \cdot 8 \%)$ of whom three died $(1 \cdot 6 \%)$. The patients have been followed on average for 32 months (range six to 72 months). Eighteen patients have subsequently required cholecystectomy $(9.6 \%)$, with six major complications, but no deaths. There have been 27 natural deaths and 156 patients remain alive and symptom free. Endoscopic treatment alone is safe and effective in the majority of frail and elderly patients and can reduce the need for surgery in this high risk group.

Obstructive jaundice caused by stones is a common disorder of the elderly. Many of these patients are fit for surgery and are treated successfully by operative clearance of the bile ducts. Unfortunately, the risks of surgical exploration of the bile ducts increase with age. A high morbidity in the elderly, with mortalities of up to $10 \%$, has been described. ${ }^{1}$ The gradual rise in the proportion of very elderly in the population means a growing number of patients are not good candidates for surgery. We have experienced an increasing number of referrals of patients for endoscopic removal of bile duct stones in patients with gall bladders present. The subsequent management of these patients is controversial and the need for cholecystectomy is disputed. It has been suggested that elective surgery is essential because of a high risk of subsequent cholecystitis. ${ }^{2-4}$ Other authors have reported low rates of late biliary surgery without many complications in patients with retained gall bladders. ${ }^{5-7}$ We have, therefore, examined the long term outcome of endoscopic biliary clearance without cholecystectomy in a larger series than previously reported, to attempt to determine the role of surgery after endoscopic clearance of the biliary tree.

Address for correspondence: Mr C J H Ingoldby, FRCS, University Department of Surgery, Clinical Sciences Building, St James University Hospital, Beckett Street, Leeds LS9 7TF.

Accepted for publication 19 December 1988.

\section{Methods}

PATIENTS

Patients were studied who had undergone endoscopic retrograde cholangiopancreatography (ERCP) for bile duct stones at Seacroft and St James's University Hospital, Leeds, between 1982 and 1987. The examinations were performed using a variety of side viewing duodenoscopes, initially a Fujinon DUOXL and latterly a Fujinon DUOXT and an Olympus TJF-10. Standard methods of cannulation and stone extraction were used, using balloons or a Dormia basket under radiological control. Clearance was assessed radiologically and, if necessary, by repeated ERCP. In some cases, where initial stone clearance was not achieved, oral dissolution therapy or temporary endoscopic stenting were used as additional manoeuvres. The procedures were undertaken by a number of operators, but always under the supervision of an experienced biliary endoscopist (MED or RIH). The large majority were performed by one person (MED). Immediate success rates were calculated from endoscopy records. Follow up data was obtained from our own records, contact with referring consultants and GPs, direct contact with patients, and hospital and family practitioner records in the case of patients who had died. Longterm results were evaluated from the recorded 
laboratory data, subsequent medical records and the patient's current state of health.

\section{Results}

ENDOSCOPIC THERAPY

One thousand six hundred and forty seven patients underwent ERCP from January 1982 to December 1987. Two hundred and seven $(12.6 \%)$ had stones in the biliary tree with gall bladders still in situ. One hundred and eighty six ( $90 \%)$ of these patients were traced and full follow up data obtained. The mean age of those followed up was 79.7 years (range 2792 ). Only 13 were aged less than 60 , of whom 11 had severe medical disorders considered to make surgery hazardous, and one was a Jehovah's witness who refused surgery. One hundred and seventy one patients were jaundiced, at the time of referral, of whom 18 also had clinical cholangitis. Ninety patients $(49 \%)$ were referred from hospital outside Leeds, of whom 33 were referred direct from surgeons.

Sphincterotomy was successful in all but one case $(99 \%)$. Drainage and complete stone clearance was achieved endoscopically in $172(92 \cdot 5 \%)$. There were two deaths associated with the procedure $(1 \%)$; one fatal haemorrhage in a 76 year old man with cholangitis, senile dementia, and periampullary diverticula, and one myocardial infarction 24 hours after drainage. Three patients suffered major complications not requiring surgery $(1.6 \%)$, one haemorrhage, one sealed perforation and one episode of pancreatitis. Four patients required immediate surgery $(2 \cdot 2 \%)$, of whom one died. One patient had a free duodenal perforation, one major haemorrhage, and two patients, including the one fatal outcome, had cholangitis and septicaemia as a result of irremovable stones. The overall death rate associated with ERCP was therefore, $1.6 \%$, and the immediate complication rate $4 \cdot 8 \%$. Complete clearance was achieved in 116 patients after one examination. Fifty nine patients needed two examinations but only 14 had remaining stones found on this examination. Five patients had more than two examinations.

Clearance was not achieved in six cases. Three of these patients underwent subsequent successful surgery, and one was successfully managed by endoscopic stenting. Two patients became temporarily less jaundiced and did not undergo further treatment. One of these died six months later of pancreatitis and the other died at three months from a stroke and bronchopneumonia.

The average hospital stay was $3 \cdot 7$ days.

FOLLOW UP

Follow up was for a mean of 32 months (range six to 72 months). Subsequent cholecystectomy for biliary problems has been needed in $18(9.6 \%)$, with six major postoperative complications but no deaths. The principal indication for surgery was persistent pain, occurring in 13 cases. Three patients had cholecystitis and in two the reason for surgery is not known. There have been 27 natural deaths from conditions unrelated to the liver and biliary tree and 156 patients remain alive and symptom free.

\section{Discussion}

The patients in this series were a highly selected group. They were elderly and the large majority were considered unfit for surgery by their doctors. Only one patient could be identified in whom recognised surgical risk factors were not present. Surgical exploration of the common bile duct in such patients has been estimated to have a mortality approaching $10 \%$, with a corresponding morbidity. ${ }^{189}$ The procedural mortality of $1.6 \%$ in our patients therefore compares favourably with reported surgical results. ${ }^{11}$ "Similar mortality figures have also been described in smaller series. ${ }^{2.57}$ There seems little doubt that endoscopic sphincterotomy has major advantages in the immediate management of the elderly and infirm with obstructive jaundice. Our average hospital stay of 3.7 days indicates that there are also economic advantages to non operative treatment.

Complete clearance of the duct normally occurred after sphincterotomy as stones which were not removed at the initial procedure frequently passed spontaneously. A small proportion of patients, $7 \cdot 5 \%$ in our series, still had stones present at the second examination, either because of narrowing of the ducts or abnormally large stones. Oral dissolution therapy with chenodeoxycholic acid or Rowachol may reduce the size of these stones and facilitate extraction. ${ }^{12}$ In others endoscopic stenting may provide complete relief of jaundice. Only three of our patients underwent surgery for persistent failure to clear the bile ducts. One patient who declined further procedures after insertion of an endoprosthesis has continued symptom free, passed the stent spontaneously after two years, and has no problems to date.

The subsequent management of the gall bladder left in situ after duct clearance remains controversial. It has been reported that about $15 \%$ of asymptomatic middle aged patients with gall stones eventually require cholecystectomy. ${ }^{13}$ For this reason it has been argued that elective cholecystectomy should be performed whenever possible to prevent late complication such as acute cholecystitis. ${ }^{2-1}$ Only a small proportion of patients in these series have been reported to actually undergo surgery, with only $10-25 \%$ agreeing to cholecystectomy. It is clear, 
Table Results of patients treated endoscopically without elective cholecystectomy

\begin{tabular}{|c|c|c|c|c|c|c|}
\hline Author & $n$ & $\begin{array}{l}\text { Mean age } \\
\text { (median) }\end{array}$ & $\begin{array}{l}\text { Procedural } \\
\text { complication } \\
\text { rate }(\%)\end{array}$ & $\begin{array}{l}\text { Late biliary } \\
\text { complications } \\
(\%)\end{array}$ & $\begin{array}{l}\text { Late } \\
\text { mortality }\end{array}$ & $\begin{array}{l}\text { Mean } \\
\text { follow up } \\
\text { (months) }\end{array}$ \\
\hline Present series & 186 & $79 \cdot 7$ & $4 \cdot 8$ & $9 \cdot 6$ & 0 & 32 \\
\hline Davidson et al ${ }^{7}$ & 106 & $(79 \cdot 0)$ & $16 \cdot 0$ & $9 \cdot 4$ & 0 & 30 \\
\hline Martin and Tweedle ${ }^{6}$ & 81 & 76 & $8 \cdot 0$ & $11 \cdot 0$ & 0 & 24 \\
\hline Escourou et al ${ }^{5}$ & 130 & $79 \cdot 0$ & $7 \cdot 0$ & $12 \cdot 0$ & 0 & 22 \\
\hline
\end{tabular}

that few patients are willing to undergo an additional elective procedure. Moreover, a policy of early cholecystectomy does not abolish the need for later surgery, with rates of $3-6 \%$ reported and late mortality of up to $2 \% .{ }^{34}$

A different policy was adopted for our patients. Surgery was reserved for early complications and significant recurrent symptoms. The Table compares our results with those of others who have adopted a similar policy. These patients have a limited expected survival because of the high frequency of associated medical disorders. The follow up periods shown therefore represents a significant proportion of their remaining lives. Some further biliary disease may be expected in survivors but we consider that the results strongly support a conservative surgical policy in these high risk patients. In most cases it is equally effective, safer, cheaper, and more acceptable to the patient.

\section{References}

1 Dixon JM, Armstrong CP, Duffy SW, Davies GC. Factors affecting morbidity and mortality after surgery for obstructive jaundice: a review of 373 patients. Gut 1983; 24: 845-52.

2 Rosch W, Riemann JF, Lux G, Lindner HG. Longterm follow up after endoscopic sphincterotomy. Endoscopy 1981; 13: 152-3.

3 Safrany L, Schott B, Balint T. Endoscopic sphincterotomy: the long term results in choledocholithiasis. Gastrointest Endosc 1982; 28: 152A.

4 Tanaka M, Ikeda S, Yoshimoto H, Matsumoto S. The long term fate of the gallbladder after endoscopic sphincterotomy: Complete follow up study of 122 patients. Am J Surg 1987; 154: 505-9.

5 Escourrou J, Cordova AJ, Lazorthes F, Frexinos J, Ribet A. Early and late complications after endoscopic sphincterotomy for biliary lithiasis with and without gallbladder in-situ. Gut 1984; 25: 598-602.

6 Martin DF, Tweedle DEF. Endoscopic management of common duct stones without cholecystectomy. Br J Surg 1987; 74: 209-11.

7 Davidson BR, Neoptolemos JP, Carr-Locke DL. Endoscopic sphincterotomy for common bile duct stones in patients with gallbladders in-situ considered unfit for surgery. Gut 1988; 29: 114-20.

8 Pitt HA, Cameron JL, Postier RG, Gaducz TR. Factors affecting mortality in biliary tract surgery. Am J Surg 1981; 141: 61-71.

9 Blamey SL, Fearon KCH, Gilmour WH, Osborne DH, Carter DC. Prediction of risk in biliary surgery. $\mathrm{Br} J$ Surg 1983; 70: 535-8.

10 Vellacott KD, Powell PH. Exploration of the common bile duct: a comparative study. Br J Surg 1979; 66: 38991.

11 Ronkema JA, Carol EJ, Liev F, Jakimowicz JJ. A retrospective study of surgical common bile duct exploration: ten years experience. Neth J Surg 1986; 38: $11-4$.

12 Sommerville KW, Ellis WR, Whitter BH, Balfour TW, Bell GD. Stones in the common bile duct: experience with medical dissolution therapy. Postgrad Med J 1985; 61: 313-6.

13 McSherry CK, Ferstenberg H, Calhours F, Lahman E, Virshup M. The natural history of diagnosed gallstone disease in symptomatic and asymptomatic patients. $A n n$ Surg 1985; 202: 59-63. 